\title{
Managing Conflicts in Joint Venture Projects
}

\author{
S. B. Abd-Karim ${ }^{1 *}$, D.A. Abg Marani ${ }^{2}$, M. S. Mohd Danuri ${ }^{3}$ and O. Mohamed ${ }^{4}$ \\ 1234 Department of Quantity Surveying, Faculty of Built Environment University of Malaya, Kuala Lumpur, \\ Malaysia \\ *1 $\underline{\text { saipolbari@um.edu.my }}$
}

\begin{abstract}
A joint venture (JV) involves two or more businesses pooling their resources and expertise to achieve a particular goal, where the risks and rewards are shared. JV has become popular because of their importance as a strategic alternative in global competition. The number of JV has increased over the past two decades due to intensified technology, competitive challenges and market globalisation but it is important to understand what causes some JV to fail and others to succeed. Conflict is the main reason that causes some JV to fail. It may create problems in future planning and have negative effects on the financial performance of the firm that would affect JV survival. Hence, the study concentrates on the JV relationship between partners in the Malaysian construction industry in order to identify the effective ways in managing conflicts. A total of 100 questionnaires were distributed to the selected respondents and the finding shows that all of the respondents experienced conflict in the JV and the conflict management team seems to be inexistent to manage the conflict. Some recommendations in managing conflict are dictated by discussing the problem such as open talk, self-patience, endurance and being decisive as well as educating all the staffs in handling conflict.
\end{abstract}

Keywords: joint venture, managing conflicts, construction industry

\subsection{INTRODUCTION}

At present, the Malaysian property and construction companies are increasingly seeking to work internationally. Companies enter into international markets through various strategies and, typically, the property and construction professionals rely on developing various forms of cooperative and collaborative arrangements. Joint venture (JV) is one of the common modes of cooperative between two or more people to invest in a specific business or property opportunity. Preece and Hasan (2010) described the benefits of JV which includes the costs and risks of the projects are spread between partners, improvement in access and financial resources, better access to new technologies and customers. Furthermore, as capital invested in JV requires the commitment between partners, it increases the probability of success (Beamish \& Lupton, 2009).

When the Ninth Malaysian Plan (9MP) was announced in 2006, the implementation of constructions projects under the 9MP is expected to provide growth in the construction sector as its main thrust focuses on the development of human capital and the services industry (Adnan, 2008). Additionally, the 9MP is said to be a good indicator (Adnan, 2008) as there will be more constructions and upgrades of education centres, hospitals and tourist destinations as well as improvement of infrastructure facilities. Malaysia is one of the leading countries in the South East Asia involved in international contracting (CIDB, 2005) of which, Malaysia is said to be in the right track to achieve its vision of becoming fully industrialized by 2020 (Adnan et al., 2011). The CIDB (2005) report indicated that Malaysian companies are participating in a variety of construction projects in over 30 countries where collaborating with foreign parties is an opportunity for Malaysian contractor to accumulate knowledge, experience and improves capability in management of such venture (Adnan et al., 2012). 
Meanwhile, in recent years, the property development in Malaysia had escalated and the property market has shown excellent development. This can be seen during the past years, where the joint venture development on apartment had increased by $60 \%$ and the sales on landed properties had a stable $20 \%$ growth (MIDA, 2012). In other words, more foreign parties are investing in new property development or construction projects and such trend looks destined to sustain in the near future, thus showing a bright future in the property market in Malaysia.

The number of international joint venture (IJV) has a steady increase (Beamish \& Delios, 1997) as firms are finding that it is desirable, and often very necessary to compete globally in order to become successful (Fey \& Beamish, 2000). Generally, IJV is not the easiest forms of organisation to manage and operate due to competitive construction businesses (Minja et al., 2012). According to Stewart and Maughn (2011), IJV must be practical, living and evolving relationships. Adnan et al. (2012) asserts that going international are viewed as a process of foreign market entry which a firm moves from operating in its domestic place to international markets. A successful IJV enhances the partners' economic performance as the result of risk reduction, economies of scale and scope, production rationalisation, convergence of technologies, and better local acceptance (Ding, 1997). There are numerous opportunities for conflict and disagreement among the partners although firms engage in joint ventures because of the need to cooperate as stated in Ding (1997). Therefore, IJV may cause a frustrating experience or failure if it is lacking of adequate planning and strategy (Stewart \& Maughn, 2011).

Conflict may result in the unwillingness of parent firms to contribute resources that the IJV needs to achieve its goals (Julian, 2008). Based on a study conducted by Ding (1997), conflicts between IJV partners significantly reduce IJV performance, thus, it is suggested that the partners need to formulate an effective conflict management strategy for IJV success in which managing conflicts in JV can be in various methods. Thus, this paper presents the effective ways in managing conflicts in JV relationship between partners from the perspectives of construction companies in the Malaysian construction industry. Termination of JV may not define its failure if one or more partners willingly sell the equity stakes to another partner or external firm (Hennart et al., 1998).

\subsection{THE EMERGENCE OF JV AND OCCURENCE OF DISPUTE IN JV PROJECTS}

The IJV phenomenon is becoming increasingly popular (Adnan, 2008; Julian, 2008;) as it allows participating companies to rapidly change the scale or scope of their business both in multinational construction firms and local government in order to achieve their JV objectives. Furthermore, Adnan (2008) stated that JV is established to take advantage of the economic, political and social conditions prevailing in a particular economy. In essence, JV by definition may involve two or more parties to achieve specific objectives whereby each party contributes to the JV either by technology transfer, shared risk or contributions in assets through an entity legally regulated by a jurisdiction (Adnan, 2008; Harrigan, 1988; Kobayashi et al., 2009; Mohammad \& Torrance, 2005; Wallace, 2004; Wolf, 2000).

Matthews (1999) highlighted that the characteristics of JV have gradually emerged over the past 20 years and, therefore, it now requires a higher degree of organisational understanding for it to be successful. There are four main characteristics of JV identified by Buchel et al. (1998), namely, viability, stability, structure, and complexity management. Buchel et al. (1998) also argued that in order for a JV to be economically and technically viable, it needs to produce goals or services for which the venture will obtain profit in return. The stability of a JV is defined as its ability to adapt to changes and new surroundings while maintaining the venture in its organised form. Thus, a venture needs to be stable for it to become viable because venture has a high instability due to the effect of interaction between groups of people with different roles and cultures. Additionally, each entity must provide access to the resources needed to each other in fulfilling a particular objective (Beamish \& Lupton, 2009).

A JV may be profitable at one point of time but it is never guaranteed that it will continue to exist in any particular industry (Buchel et al., 1998). Generally, the life-cycle of a JV consists of six stages; the initiation stage, the early partner agreements stage, the learning stage, the changes in dependency stage, the buy-out discussions stage and finally the termination stage. All venture businesses have their benefits and challenges and there is no exception for JV business (Derco, 2012). The benefits of JV are the advantages of local contacts, combined talents and resources, additional working capital sources, knowledge transfer and risk sharing. 
Mahmud and Zhi (2009) affirmed that teaming up a foreign contractor with local contractors that may have political or valuable relationships in the country can benefit the joint venture. Moreover, a JV can also be formed between partner firms in pooling resources and talents to pursue a common interest or cooperative advantages. Two or more contractors are allowed to pool their expertise, resources and knowledge as well by sharing financial strength, workforce, equipment and bonding capacity while sharing the risks involved in completing a project (Derco, 2012). Sharing financial resources can make two smaller companies to achieve economies of scale similar to those that are enjoyed by their larger competitors (Mahmud \& Zhi, 2009). According to Turner and Simister (2001), a JV is appropriate for projects of high uncertainty because the client and contractors can share both project risk and uncertainty through an alliance.

Disputes are common in any organisation but its worst effects are seen when the management is composed of a mixture of people from different entities. Matthews (2001) asserted that the challenges in JV management are the collection of individuals with differences in culture, geographical locations and organisation politics of joint-venturing. Furthermore, disputes among JV organisation can be confrontational, time-consuming, distracting, as well as highly destructive of value (Simmons \& Simmons, 2014). Factors that contribute to the problems in implementing a JV includes differing size of organisations between participating partners, difficulties in establishing inter-partner trust, mutual understanding, and inconsistencies in management practice. According to Adnan et al. (2012), these problems are the barriers to the JV and are possible causes of dispute.

Conflict exists within an organisation and is endemic irrespective of whether or not it is desirable (Omiko \& Rout, 2007). Besides that, conflict also exists when two or more party are mutually inconsistent (Nicholson, 1992), or when the competing resources are considered (Pickering, 2000). Meanwhile, Fey and Beamish (2000) found that a conflict between parent or partner firms is one of the most common reasons of JV failure. It may arise due to a variety of factors, which may be an overt expression of tensions between goals or concerns party, differing expectations, values, and proposed course of action or suggestion about how best to handle a situation (Omiko \& Rout, 2007). It also occurs when people perceived that their interests are not well-matched with other people in a group, firm, or society (Shih \& Susanto, 2010).

A conflict is resolved when some mutually compatible set of actions is worked out (Nicholson, 1992). However, Julian (2008) argues that a small amount of conflict may be healthy for the joint venture since it may force management to evaluate their decisions more carefully. The existence of conflict requires managers to spend valuable time and effort in resolving or managing the conflict, preventing this time from being spent in more productive ways (Julian, 2008; Omiko \& Rout, 2007). Organisations have to deal with conflict all the time (Mansor, 1998) as conflicts may hint towards a potentially serious situation in the organisation that needs attention (Omiko \& Rout, 2007). The unresolved conflict often creates serious and quite varied consequences. The consequences ranges from work issues of responsibility, power, authority, and ethics which would adversely affect the company's performance (Mansor, 1998), leading to project delays, damaging customers' relation, declining morale as well as productivity (Omiko \& Rout, 2007).

Managing conflict focuses on maintaining it at the right level to help the department, work unit or organisation reach its goals (Omiko \& Rout, 2007). However, examining the conflict nature without knowing the appropriate approaches to handle the conflict only solves half of the problem (Liu et al., 2008). Thomas (1976) develops a framework that describes conflict-handling approaches in terms of whether individuals have more concerns for themselves or for others. The framework has two dimensions, including: cooperativeness, when individuals' willing to meet the needs and concerns for others are higher; and assertiveness, when individuals' willing to satisfy its own needs and the concerns for self are higher. Alongside these two dimensions, five approaches were identified which are collaborating, competing, accommodating, avoiding and compromising. These conflict-handling approaches reflect how individuals or teams negotiate between their own and the other party's interests while dealing with a conflict. The Thomas-Kilmann model of conflict resolution is a widely used approach to understand different ways people deal with conflict (Omiko \& Rout, 2007).

\subsection{METHODOLOGY}

This research adopts quantitative method in collecting empirical data. A questionnaire survey has been developed which consists of 39 questions. The questionnaire is categorized into four (4) sections comprising of closed-ended and some 
open-ended questions. The questionnaire is answered in the form of checklist and Likert scale. The respondents chosen for this research were among the registered grade G7 contractors within the Federal Territory of Kuala Lumpur listed on the Construction Industry Development Board (CIDB), Malaysia directory. Established in 1994, CIDB is a statutory body enacted under the Laws of Malaysia (Act 520) which coordinates and maintains the registration of all contractors. Contractors are entitled to be registered in particular categories of construction works such as civil engineering, building and mechanical and electrical works (Mohamed et al., 2014). There are seven specified registration grades, G1 to G7 with differing tendering capacity as shown in Table 1. However, this research focuses on G7 contractors that have the ability to acquire projects that costs MYR 10,000,001.00 and above for building, civil and mechanical works and MYR 200,001.00 and above for electrical works. A registered G7 contractor must have at least MYR 750,000 of accumulated capital for sole proprietor firm or partnership in the form of bank statements for the last 3 months or capital paid for 'Sendirian Berhad or Berhad' companies in addition to employing a project manager who is accredited by CIDB.

Table 1: CIDB's contractors' registration grades and tendering capacity limit

\begin{tabular}{|c|l|l|}
\hline Registration Grade & \multicolumn{1}{|c|}{ Building, Civil \& Mechanical Works } & \multicolumn{1}{|c|}{ Electrical Works } \\
\hline G1 & MYR 200,000.00 and below & MYR 200,000.00 and below \\
\hline G2 & MYR 200,001.00 - MYR 500,000.00 & MYR 500,000.00 and below \\
\hline G3 & MYR 500,001.00 - MYR 1,000,000.00 & MYR 1,000,000.00 and below \\
\hline G4 & MYR 1,000,001.00 - MYR 3,000,000.00 & MYR 200,001.00 - MYR 3,000,000.00 \\
\hline G5 & MYR 3,000,001.00 - MYR 5,000,000.00 & MYR 200,001.00 - MYR 5,000,000.00 \\
\hline G6 & MYR 5,000,001.00 - MYR 10,000,000.00 & MYR 200,001.00 - MYR 10,000,000.00 \\
\hline G7 & MYR 10,000,001.00 and above & MYR 200,001.00 and above \\
\hline
\end{tabular}

Source: http://www.cidb.gov.my

However, due to the large populations of the registered G7 contractors in Kuala Lumpur, only those listed in Bursa Malaysia (stock exchange) were selected. Additionally, due to the constraint of time in conducting this research, only 100 questionnaires were distributed randomly using 3 methods, namely, by mail, by electronic mail or email and by hand. The data from the returned questionnaire surveys were analysed in three stages which were the primary analysis, detailed analysis and final analysis. The primary analysis is where the preliminary data concerning the respondent's background and the company's details are gathered and identified. Then, all of the data collected and compiled from the questionnaire are analysed using Statistical Package for Social Science (SPSS) and Microsoft Excel with two (2) types of test that includes Pearson correlation analysis and frequency table. The final analysis is conducted to come up with the results and recommendations for this research.

\subsection{FINDINGS}

There were only 31 respondents took part in the survey and one questionnaire form was returned incomplete. Thus, it made the total of valid questionnaires to be 30. Figure 1 shows that respondents who involved with civil engineering works such as highways, roads and dam contribute to the highest percentage, which are $38.88 \%$. The second highest percentage is the respondents involved with building works which contributed to $33.33 \%$. On the other hand, the services work contributed to $16.67 \%$. Mechanical and electrical engineering as well as other types of construction work such as foundation works both contributed to $5.56 \%$. In addition, some of the organisation involved in more than one (1) type of construction works. 


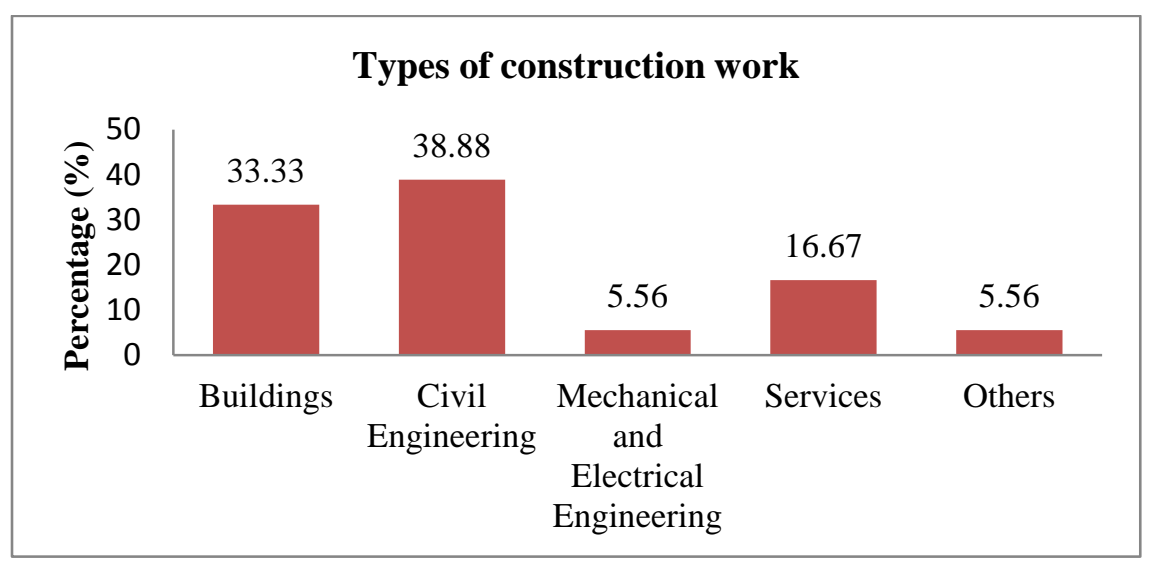

Figure 1: Types of construction work

Figure 2 shows that the population of organisations the respondents worked in which involved JV. 70\% of the organisation who responded with the questionnaire involved in JV while the remaining $30 \%$ does not involved in JV.

\section{Have your organization been involved in JV}

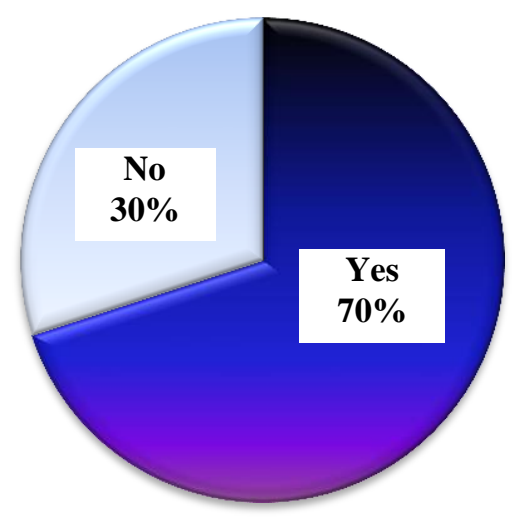

Figure 2: Organisations' involvement in Joint Venture

Questions were asked about the duration and the number of projects that the respondents have involved through JV. A simple Pearson bivariate correlation is used to explore the relationship between the two variables.

Table 1: The relationship between the duration and the number of project in joint venture

\section{Correlations}

\begin{tabular}{|ll|r|r|}
\hline & & How long involved in JV & Number of project \\
\hline \multirow{4}{*}{ Duration involvement with JV } & Pearson Correlation & 1 & $.849^{* * *}$ \\
& Sig. (2-tailed) & & .000 \\
& $\mathrm{~N}$ & 30 & 30 \\
& Pearson Correlation & $.849^{* * *}$ & 1 \\
\hline Project number & Sig. (2-tailed) & .000 & 30 \\
& $\mathrm{~N}$ & 30 \\
\hline
\end{tabular}

** Correlation is significant at the 0.01 level (2-tailed) 
Table 1 shows the relationship between the duration of an organisation involved in JV and the number of project accomplished that was investigated using Pearson correlation analysis. There was a strong positive correlation between these two variables, $\mathrm{r}=0.849, \mathrm{n}=30$, with longer involvement in joint venture associated with higher number of joint venture projects. Figure 3 presents a chart for the relationship between the two variables. This research discovered that the duration involving in joint venture is directly proportionate with the number of joint venture projects. Therefore, it is safe to say that the longer a company involved with joint venture, the higher the number of joint venture projects they will involve in.

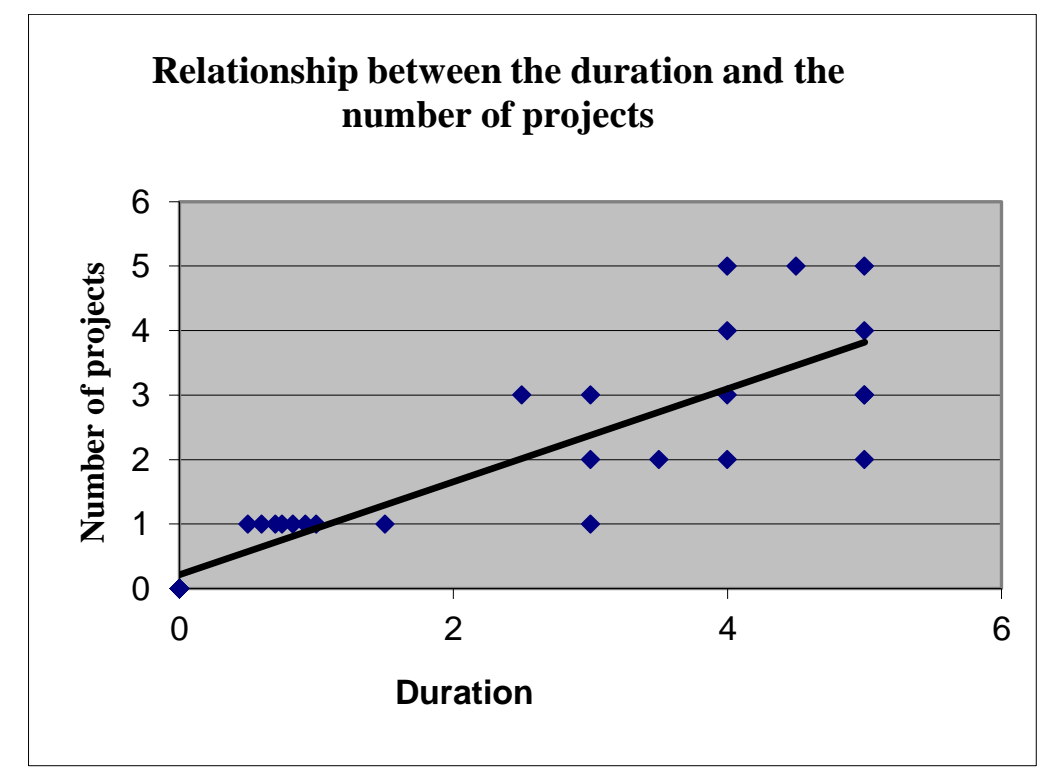

Figure 3: The relationship between the duration and the number of project in joint venture

Next, the respondents were asked about their experiences in conflicts within their organisations and the JV. This question aims to investigate the presence of conflict in an organisation and the JV as a whole. The results show that all respondents had experienced some form of conflicts. This proves that generally, conflicts are present in the organisation and the JV.

\section{Which one occurs more frequently}

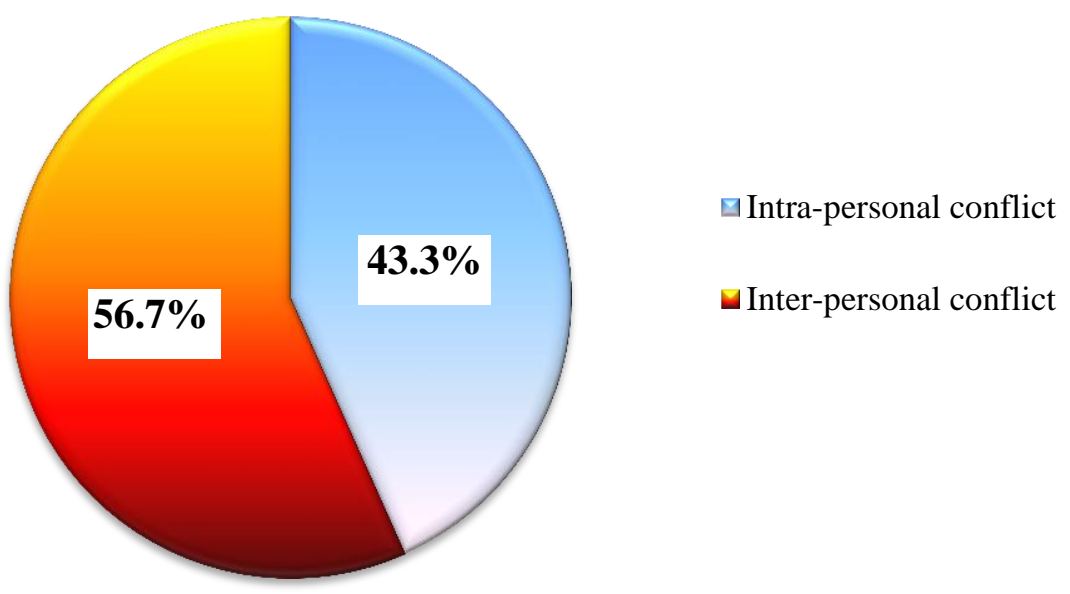

Figure 4: Type of conflict that occurred 
Figure 4 indicates that $56.7 \%$ or 17 respondents perceived that they experienced inter-personal conflict more compared to intra-personal conflict that contributes to $43.3 \%$. This shows that the respondents have usually encountered conflicts with their subordinates and superior. The following figures present in detail the potential causes of such inter-personal conflicts.

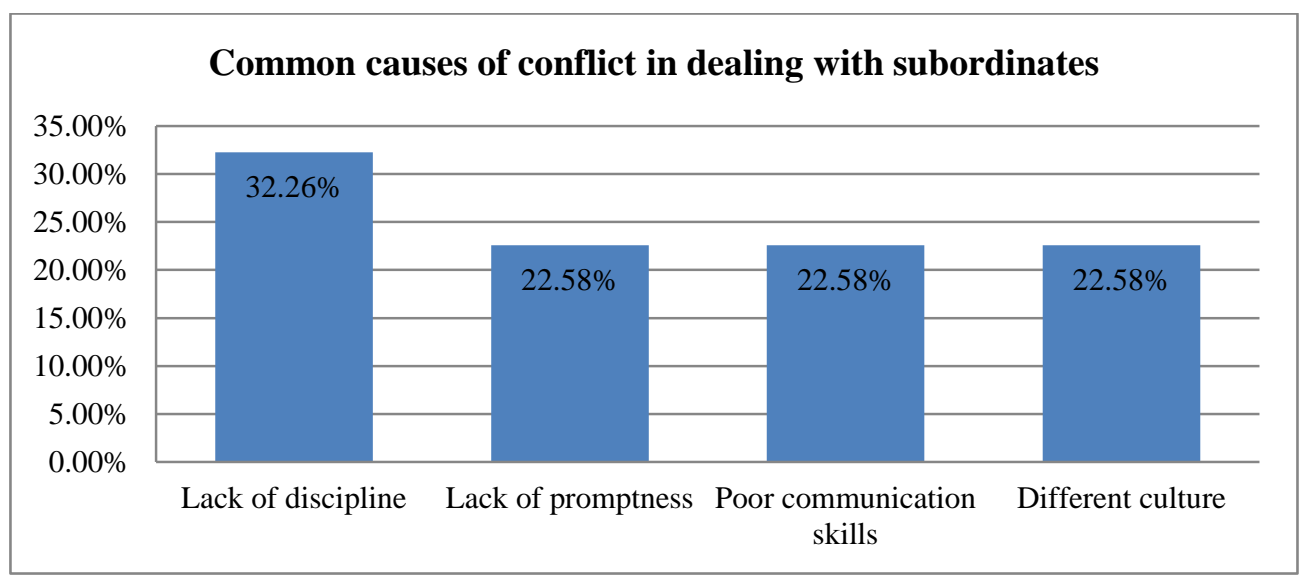

Figure 5: Common causes of conflict when dealing with subordinates

Figure 5 above shows that lack of discipline is the main cause of conflicts in dealing with subordinates. The other causes such as lack of promptness, poor communication and different culture amount to the same percentage $22.58 \%$.

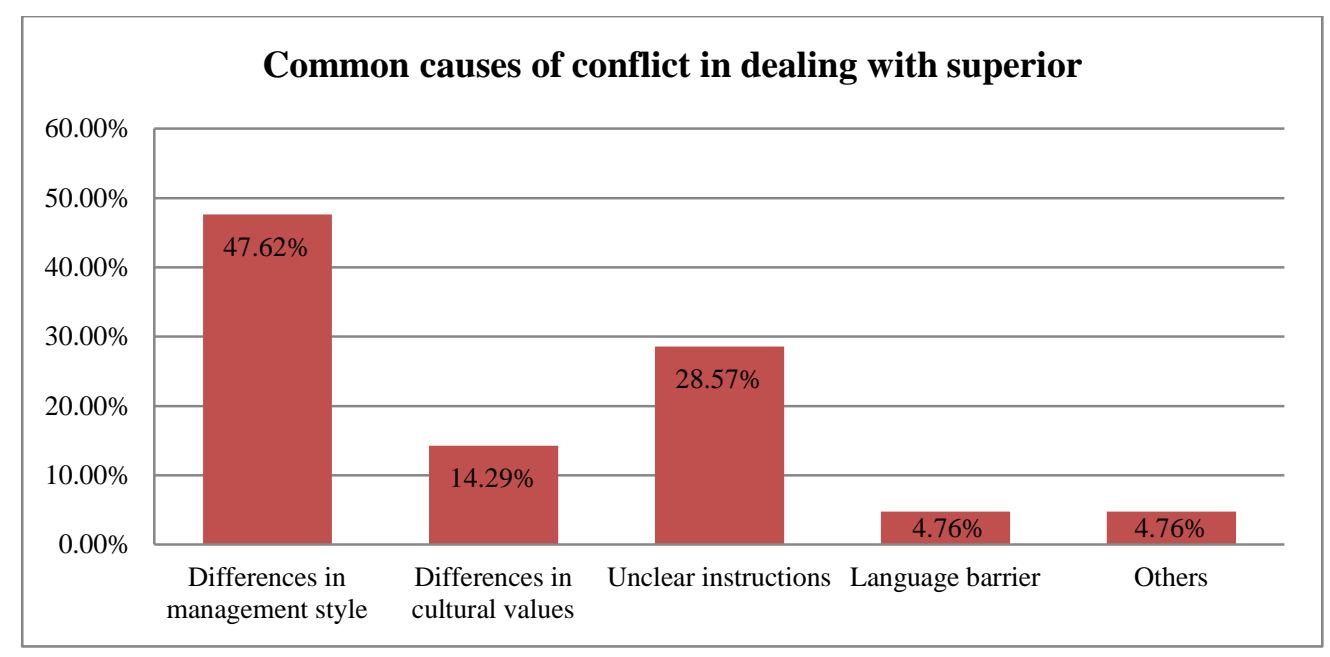

Figure 6: Causes of conflict when dealing with superior

Meanwhile, Figure 6 shows that the majority of the respondents $(47.62 \%)$ have experienced conflicts with their superior due to the differences in management style. The second highest percentage which amount to $28.57 \%$ is the unclear instructions given by the superior. Other than that, differences in cultural values contributed to $14.29 \%$ besides language barrier and others both contributed to $4.76 \%$. Some of the respondents suggested that misunderstanding and indecisiveness can cause conflict especially when dealing with superior. Next, the respondents were asked about their opinion on whether the interdependency between superior and subordinate can causes conflicts. This analysis is to identify the relationship between the attitudes of being dependent towards others and conflict. 


\section{Does interdependency causes conflict}

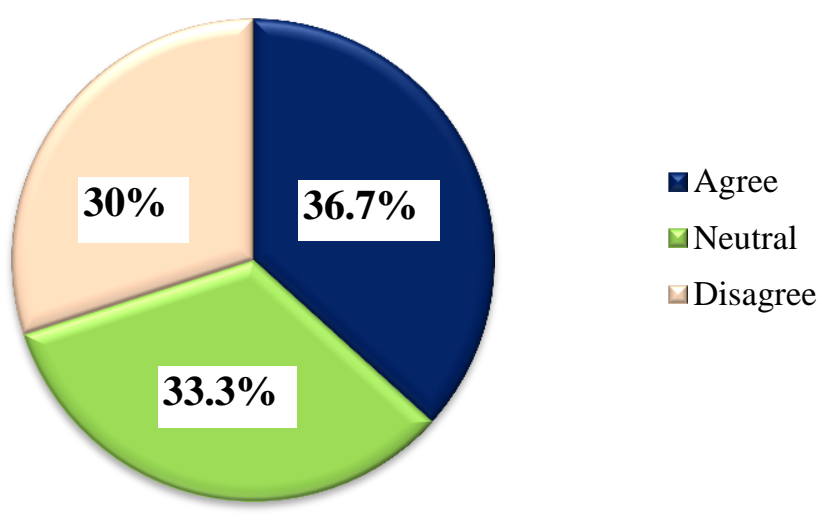

Figure 7: Interdependency between subordinates and superior to cause conflicts

Figure 7 shows that $36.7 \%$ or 11 of the 30 respondents agreed that interdependency between subordinates and superior can cause conflicts while $30 \%$ or nine respondents disagree with the statement. The remaining ten or $33.3 \%$ are neutral with this statement. It can be safely said that the interdependency between subordinate and superior may cause conflicts in an organisation and JV as well. Next, questions were asked to identify the types of intra-personal and inter-personal conflicts that occurred in the respondent's organisations.

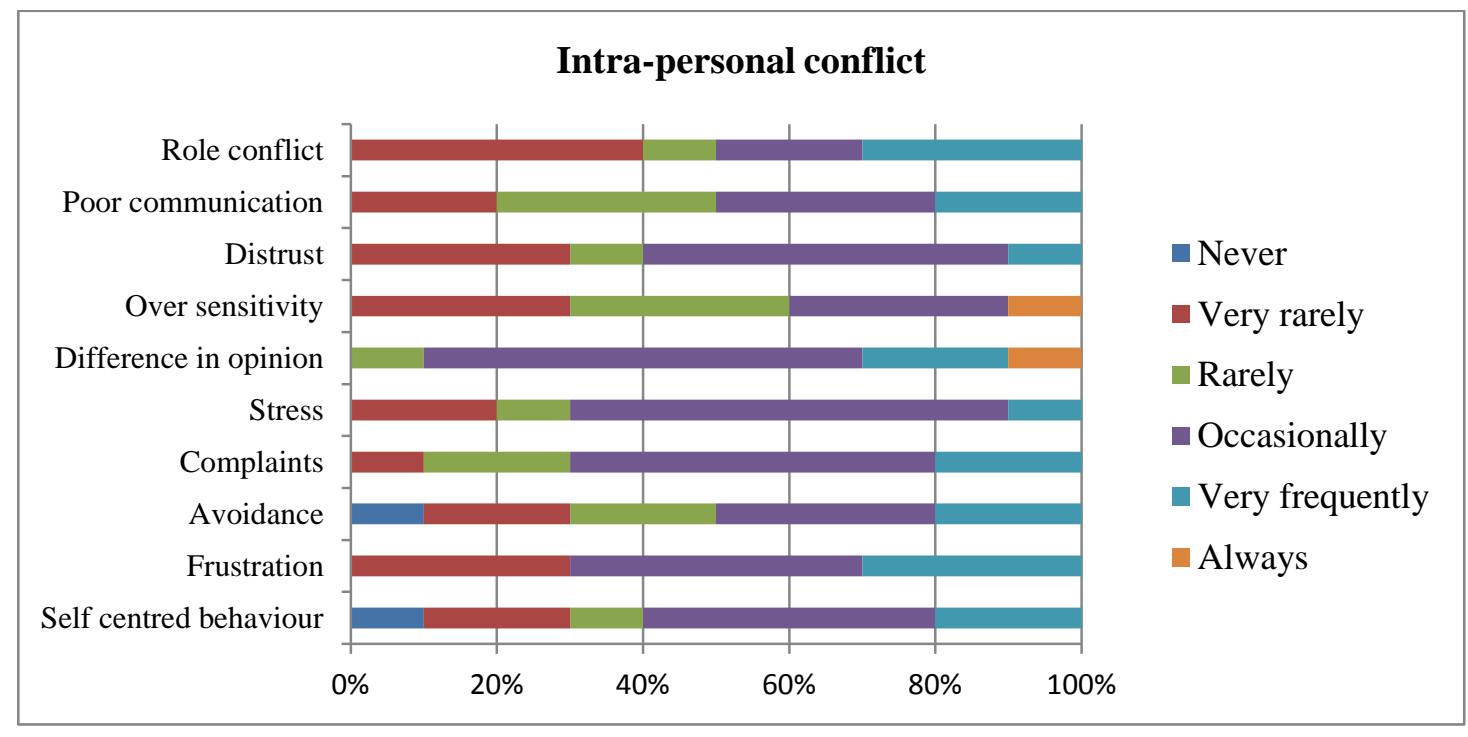

Figure 8: The intra-personal conflict that occurs in an organisation

Figure 8 shows that over sensitivity and differences in opinion conflict always occur while the role conflict, poor communication, complaints, avoidance, frustration and self-centred behaviour are seen are conflict that occurs very frequently. In addition, some respondents suggested that stress, difference in opinion, distrust and complaints happens occasionally. Generally, there are some common intra-personal conflicts that occur in an organisation and JV relationship such as difference in opinion, stress, complaints and frustration. 


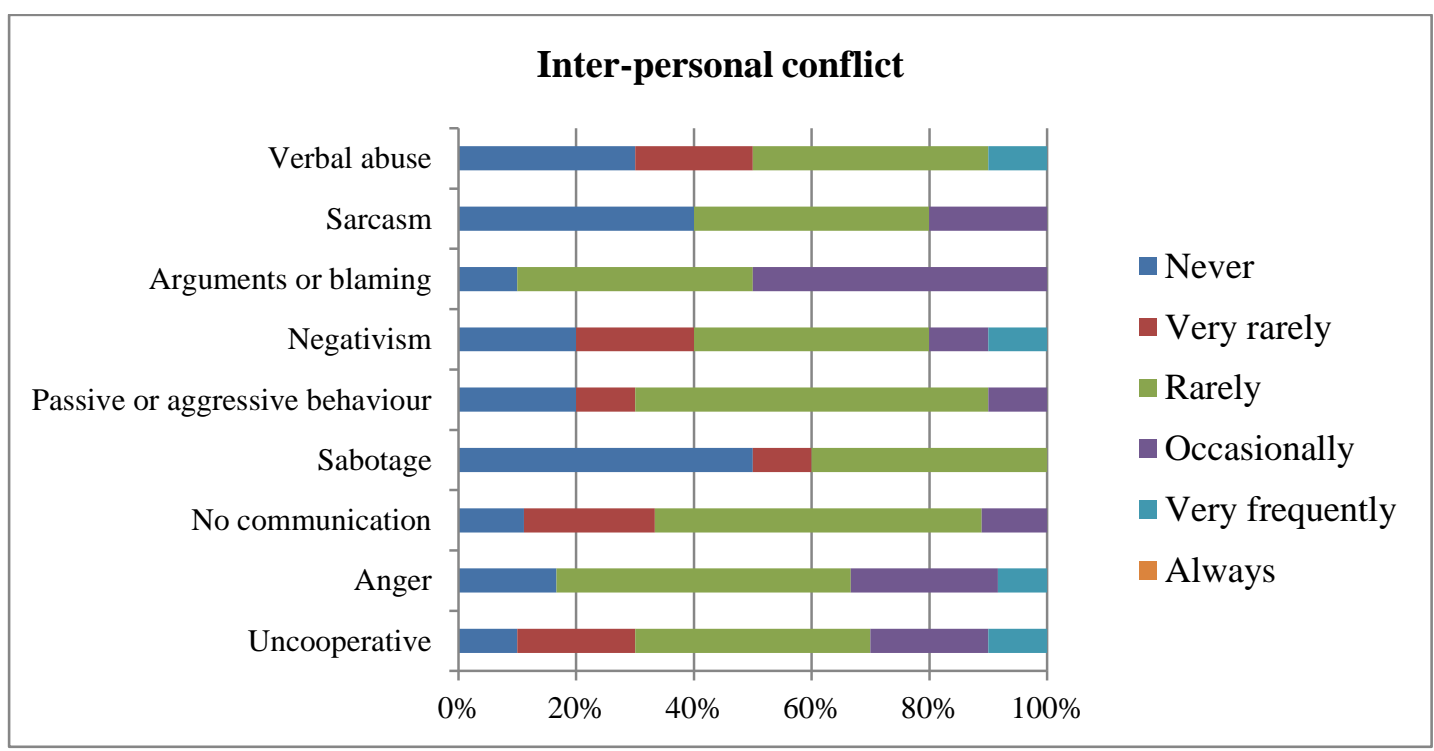

Figure 9: The inter-personal conflict that occurs in an organisation

Figure 9 above shows that verbal abuse, negativism, anger and uncooperative occurs in an organisations very frequently. Arguments or blaming and sarcasm occur occasionally. The other conflicts such as sabotage, passive or aggressive behaviour rarely happens. Similarly, there are also some common inter-personal conflicts that occur in an organisation and JV relationship such as arguments or blaming, sarcasm and uncooperative. The following Figures 10 and 11 present the defence mechanisms and precautions taken by the organisations when conflict occurs.

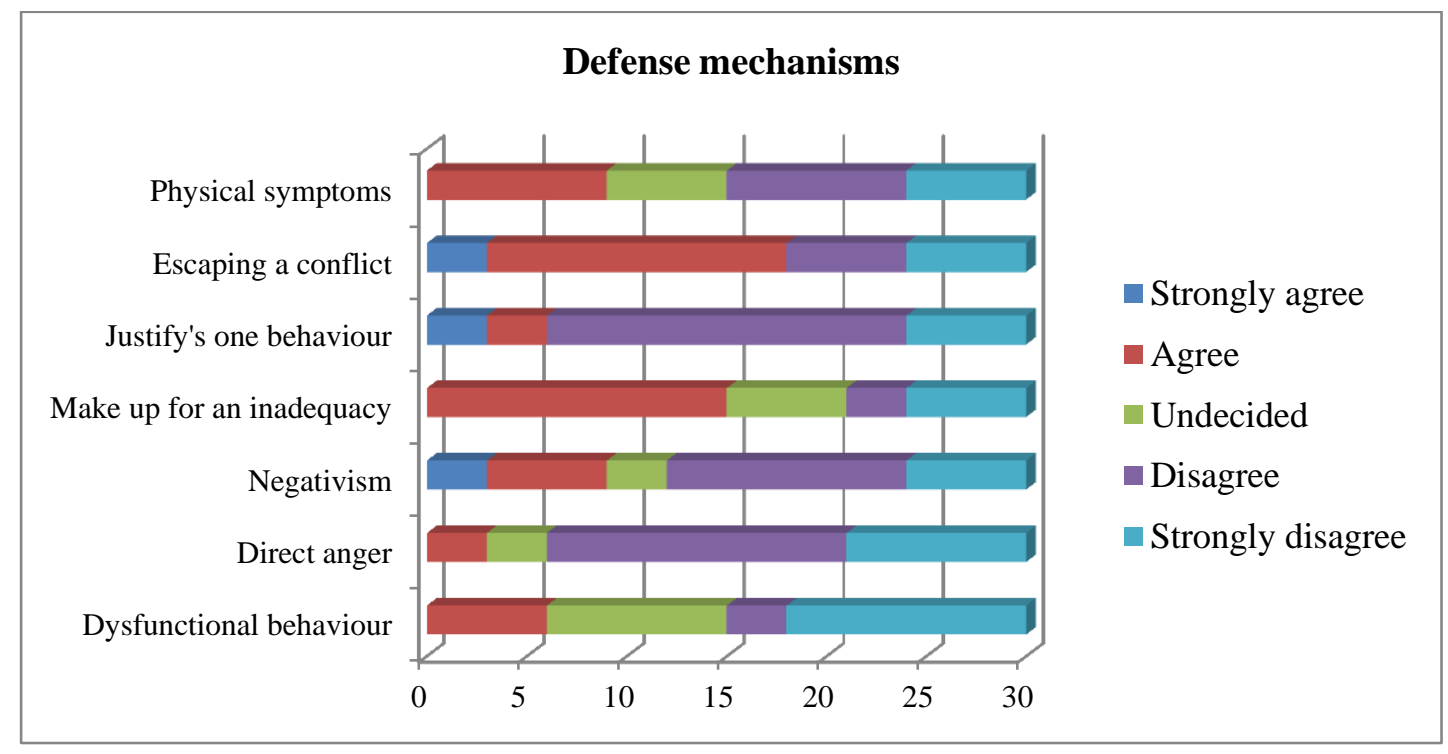

Figure 10: The defence mechanisms noticed in an organisation when conflict occurs

Figure 10 shows that whenever a conflict occurs, the person who involved in conflict either expressed their conflict in physical symptoms, make up for an inadequacy by putting extra effort into another work or escaping the conflict itself. The three (3) main defence mechanisms are escaping the conflict, justify one's behaviour by constructing false accusation and negativism. 


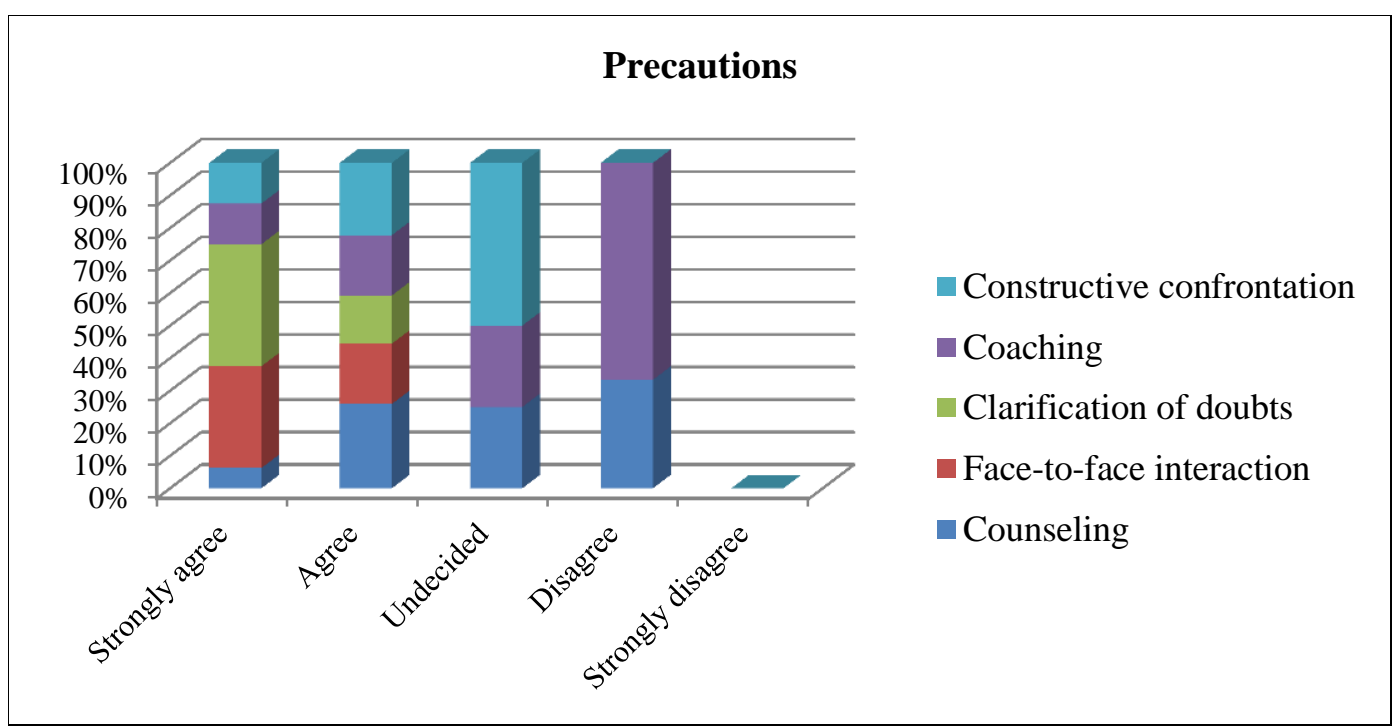

Figure 11: The precautions step taken to handle conflict

Figure 11 shows that the organisations agreed that clarification of doubts and face-to-face interaction are the best action to be taken in handling conflict. Most of the respondents disagreed with coaching and counselling method in handling conflict. Next, the respondents were asked whether there is a need to have a proper training in handling conflicts in an organisation. The result is shown in Figure 12.

\section{Do you need training}

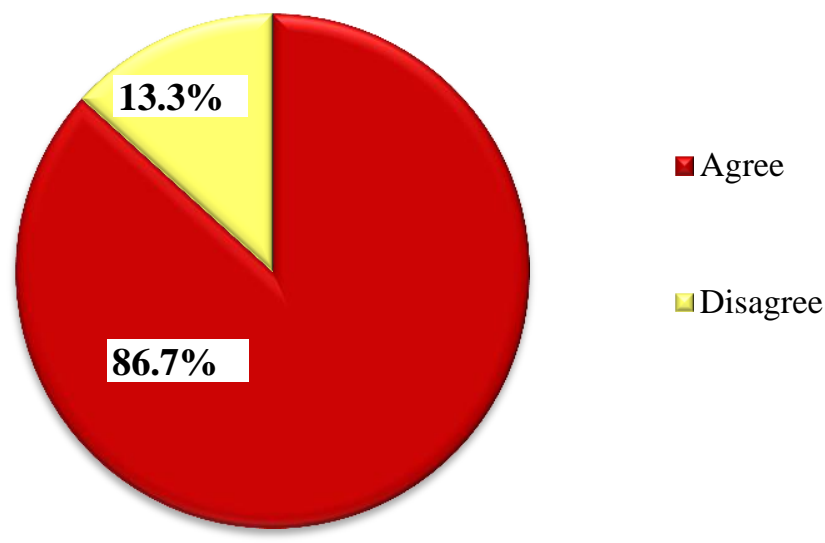

Figure 12: Needs of proper training to handle conflicts

Figure 12 shows that $86.7 \%$ of the respondents gave positive answer, in which they agree that their organisations need proper training to handle conflict, while the other $13.3 \%$ disagree. Despite of showing positive signs to conduct proper training in handling conflicts in the future, it was discovered that all respondents who experienced conflicts have never tried to implement a conflict management team in their organisations. Figure 13 illustrates that the persons who usually in charge of a conflict are the staffs, team leaders, managers and directors. Interestingly, Figure 14 shows that the department responsible in handling the conflicts is usually the human resources department rather that marketing, finance or production departments which have been collectively grouped as others. 


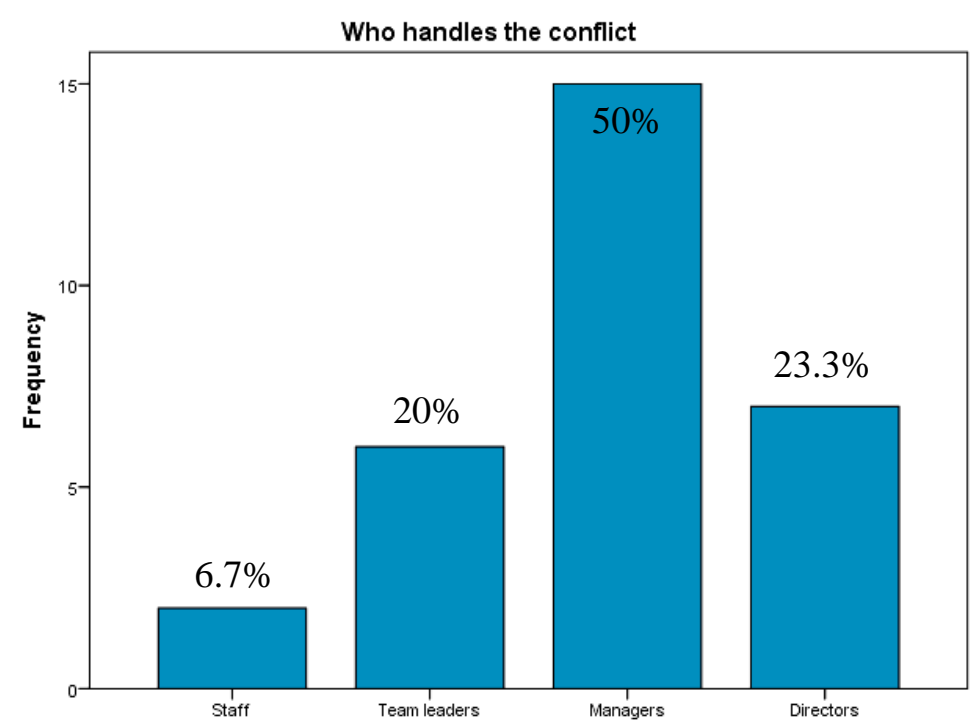

Figure 13: Position in the organisation who handles the conflict

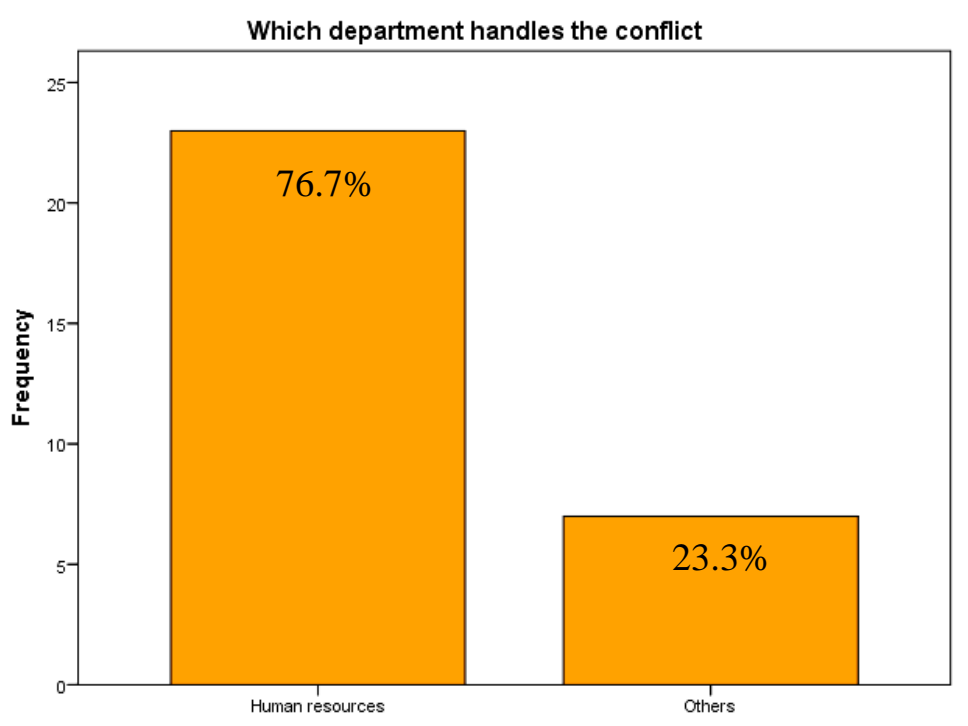

Figure 14: The department that handles the conflict

Figure 15 shows that almost half of the respondents which amount to $46.7 \%$ mentioned that their organisation uses counselling in handling conflict. The other method is by mediation which contributes the second highest percentage of $20 \%$. Coaching and other methods such as mutual discussion both amounted to $16.7 \%$. The respondents were also asked about the five management styles provided by Thomas-Kilmann that suits their organisation the best. The five management styles are competing, compromising, accommodating, collaborating and avoiding. 


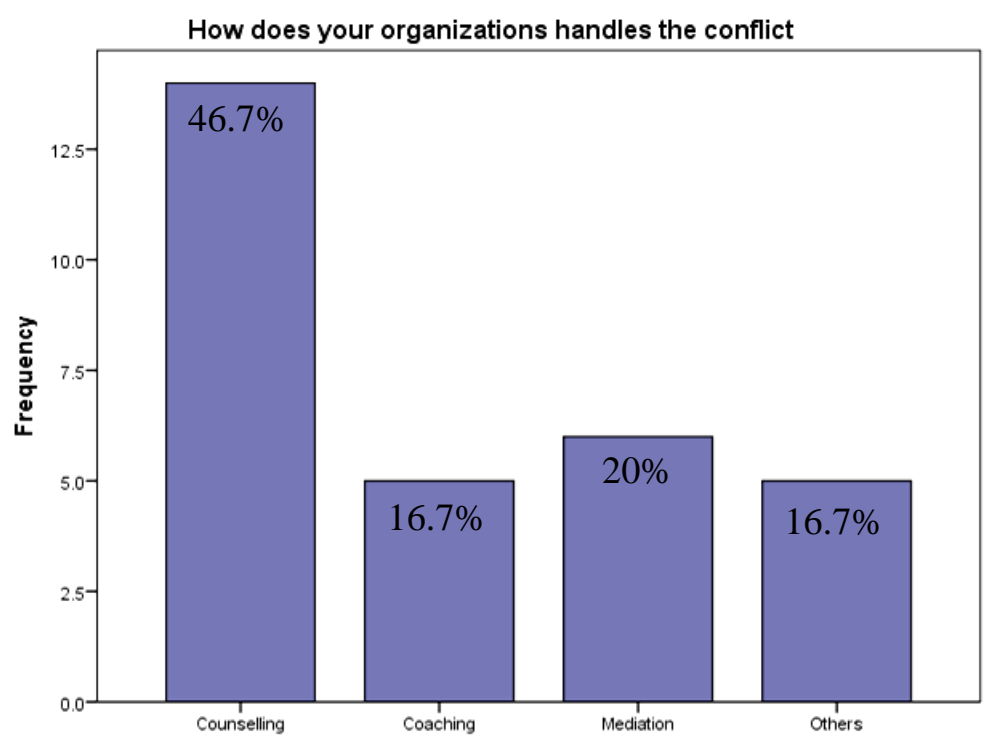

Figure 15: Method in handling conflict

Figure 16 shows that $36.7 \%$ of the respondents prefer to use collaborating style in managing conflict followed by $33.3 \%$, the accommodating style and finally $30 \%$, the compromising style. Thus, it can be confidently assumed that organisations do not prefer to use competing and avoiding style in managing conflict.

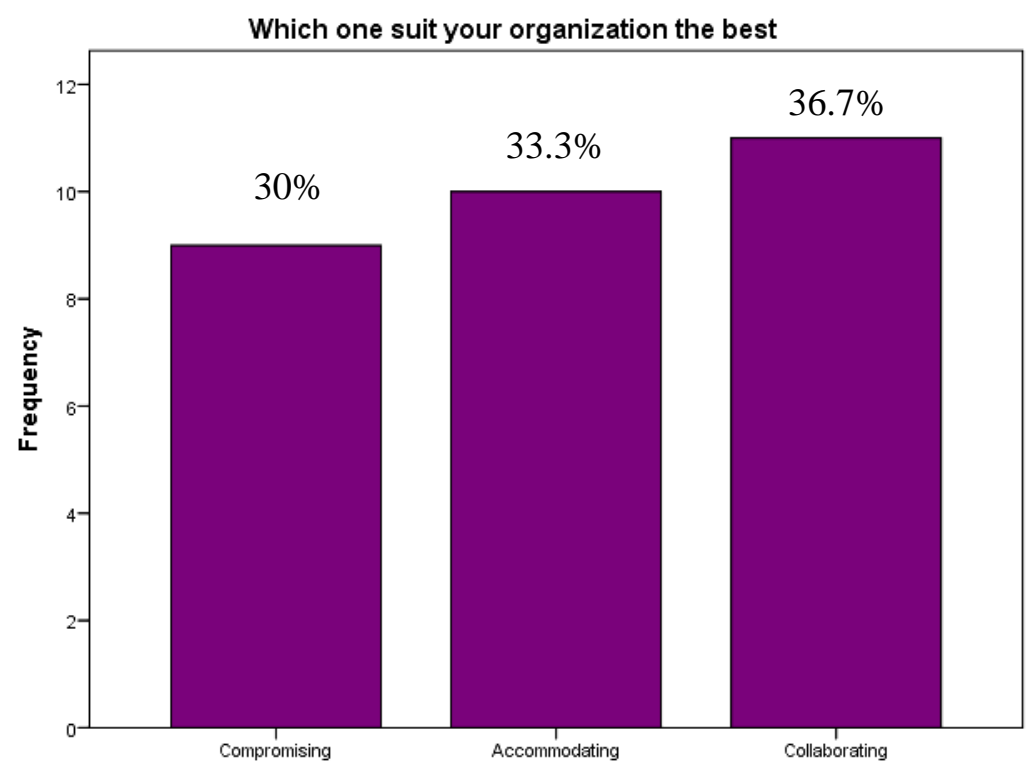

Figure 16: The type of management styles their organisations used in handling conflicts

\subsection{DISCUSSION ON THE FINDINGS}

Joint venture has become popular among construction companies who want to expand their projects to a higher level of achievement. Based on the findings, it shows that most of the respondents are involved with joint venture and all of them had experienced conflict in their organisation and JV, although joint venture deemed to decrease the probability of such issue to be arisen. This finding is consistent with the suggestions made by Omiko and Rout (2007) and also Fey and Beamish (2000) in which conflicts exist within an organisation and conflicts between parent or partner firms is one of the common reasons of 
JV failure. In essence, most of the respondents had encountered with inter-personal conflict and agreed that the interdependency between subordinate and superior can cause conflicts.

The common causes of conflict between subordinate and superior are lack of discipline, differences in management style and unclear instructions given by the superior. Thus, in the construction industry, it is the key success for the subordinates to be discipline in their works, at the same time having the superior to have an understandable management style and to give clear instructions. The common intra-personal conflict that occurs in an organisation are difference in opinion, stress, complaints and frustration while common inter-personal conflict are blaming, sarcasm and uncooperative. This finding may explain further the challenges in managing a JV which consists of a mixture of people with differences in culture, geographical locations and organisational politics of joint-venturing (Matthews, 2001). In addition, according to Adnan et al. (2012), different size of organisation between participating partners causes difficulties in the formation of JV, as well as difficulties in establishing inter-partner trust, mutual understanding and inconsistencies.

In order to avoid conflict in JV, intra-personal or inter-personal conflicts should be overcome and well-managed to ensure the harmonious working environment. This research found that the person who involved in the conflict will either escape the conflict, justify one's behaviour by constructing false accusation or negativism. Despite of their awareness that conflict may occur, they do not have conflict management team in place to handle conflict appropriately. At present, clarification of doubts and face-to-face interaction are the best step to be taken in preventing conflict. Generally, the organisations have already implemented a conflict management style and most of the respondents are comfortable with the collaborating style and it is suggested that what they really need is to have proper training to handle conflict.

Conflict management exercise should be carried out as this would make them to be well-trained and prepared to deal with conflicts especially from the very beginning to prevent it from escalated into a dispute. The importance of training as a tool in providing the effective conflict management and ensuring successful implementation of IJV have been previously highlighted by Stewart and Maughn (2011) and Ding (1997). Literature reviews have also shown that JV needs a high degree of organisational understanding if they want to be successful (Matthews, 1999). Further, according to Nicholson (1992), conflict exists when two people carry out acts which are mutually inconsistent. In this regard, this study suggests that the organisations agree that clarification of doubts and face-to-face interaction are the best step taken in handling conflict that may arise in JV.

\subsection{CONCLUSION}

This research discovers that conflict can be beneficial to the JV relationship, the industry and the economy as a whole as JV becomes a preferable entry mode to the foreign business market. JV has become the main techniques in pooling resources and expertise to achieve a particular goal, while sharing the risks and rewards in Malaysia. The effects can be harmful or beneficial to the relationship based on how the managers handle and manage the conflict. Since conflicts are inevitable, construction practitioners should embraced and handle the conflict with proper mechanisms. Therefore, establishing conflict management team in a joint venture and an organisation as a whole is very important to handle and manage the conflict appropriately and effectively as conflict can be a sign of an opportunity to change for a better future.

The benefits and the success in managing conflicts in JV would open up more construction companies to engage with this type of agreement, thus ensuring bigger project scale and scope to be carried out in the future. Going locally or internationally, JV still brings advantages in the improvement of the Malaysian construction industry. However, the management of conflict in JV is crucial in ensuring the success of a particular project. Failure in JV not only brings negative implications to the parties involved but also to future Malaysia's construction business chances, environment, investment among foreign stakeholders as well as to the people and nation, as a whole. It is suggested that if conflict is well managed, it can bring the organisation and the JV to be much more innovative and productive. It is anticipated that the individuals and organisations in charge should put in place initiative to educate their human resources through a proper training program on how to handle conflict as well as to take prompt action on a conflict before they turn into a more serious issue. 


\subsection{REFERENCES}

Adnan, H. (2008). An assessment of risk management in joint venture projects (JV) in Malaysia. Asian Social Science, 4(6), 99-106.

Adnan, H., Chong, H.Y., \& Morledge, R. (2011). Success criteria for international joint ventures: The experience of Malaysian contractors in the Middle East. African Journal of Business Management, 5(13), 5254-5260.

Adnan, H., Kassim, A.N., \& Chong, H.Y. (2012). Success factors on joint venture projects for indigenous Bumiputera contractors in Malaysia. Journal of Applied Sciences Research, 8(8), 4113-4125.

Beamish, P.W., \& Delios, A. (1997). Improving joint venture performance through congruent measures of success. Cooperative Strategies: European Perspectives. San Francisco: New Lexington Press.

Beamish, P. W., \& N. C. Lupton (2009). Managing joint ventures. Academy of Management Perspectives, 75-94.

Buchel, B., Prange, C., Probst, G., \& Ruling, C. (1998). International joint venture management: Learning to cooperate and cooperating to learn. Singapore: John Wiley and Sons (Asia) Pte Ltd.

CIDB (2005). Construction industry master plan for Malaysia (2005-2015). Construction Industry Development Board (CIDB), Kuala Lumpur, Malaysia.

Derco, S. (2012). The benefits and pitfalls of the joint venture. Journal of Construction, Accounting \& Taxation, 10(6).

Ding, D.Z. (1997). Control, conflict and performance: A study of U.S. - Chinese joint ventures. Journal of International Marketing, 5(3), 31-45.

Fey, C.F., \& Beamish, P.W. (2000). Joint venture conflict: The case of Russian international joint ventures. International Business Review, 9, 139-162.

Harrigan, K. (1988). Joint ventures and competitive strategy. Strategy Management Journal, 9(2), 141-158.

Hennart, J. F., Kim D. J., \& Zeng, M. (1998). The impact of joint venture status on the longevity of Japanese stakes in U. S. manufacturing affiliates. Organisation Science, 9(3), 382-395.

Julian, C.C. (2008). Joint venture conflict: The case of Thai international joint ventures. Journal of Asia-Pacific Business, 9(1), 6-27.

Kobayashi, K., Khairuddin, A. R., Ofori, G., \& Ogunlana, S. (2009). Joint ventures in construction. London: Thomas Telford Limited.

Liu, X., Magjuka, R., \& Lee, S. (2008). An examination of the relationship among structure, trust and conflict management styles in virtual teams. Performance Improvement Quarter, 21(1), 7-93.

Mahmud, S.H., \& Zhi, Y.H. (2009). Strategies and obstructions of joint-venture in the Malaysian construction industry. Paper presented at $13^{\text {th }}$ Pacific Association of Quantity Surveyors Congress (PAQS 2009). Kuala Lumpur, Malaysia.

Mansor, N. (1998). Managing conflict in Malaysia: Cultural and economic influences in Kwok Leung and Dean Tjosvold (eds.), Conflict Management in the Pacific Rim (pp. 147-166). John Wiley and Sons (Asia).

Matthews, C. (1999). Managing international joint ventures: The route to globalising your business. London and Dover: Kogan Page.

Matthews, C. (2001). Managing international joint ventures: The route to globalising your business, $2^{\text {nd }}$ Edition. London and Dover: Kogan Page.

Minja, S.J., Kikurasi, G.J., \& Thwala, W.D. (2012). A study of joint venture formation between construction organisation in Tanzania. Australasian Journal of Construction Economics and Building, Conference Series, 1(2), 32-42

MIDA (2012). Forging strategic business partnerships between Malaysia and IDB Member Countries. Paper presented at Malaysia Islamic development bank group investment forum. 9-11 May 2012, Kuala Lumpur.

Mohammad, M., \& Torrance, J. V. (2005). Critical success factors in Malaysian construction joint ventures. International Conference on Multi-National Joint Venture for Construction Works, Penang, Malaysia.

Mohamed, O, Abd-Karim, S.B, Roslan, N.H, Mohd Danuri, M.S, \& Zakaria, N. (2014) Risk management: Looming the modus operandi among construction contractors in Malaysia. International Journal of Construction Management, (forth coming).

Nicholson, M. (1992). Rationality and the analysis of international conflict. Cambridge: Cambridge University Press.

Omiko, N., \& Rout, E.L. (2007). Corporate conflict management concepts and skills. New Delhi: Prentice-Hall of India Ptd Ltd.

Pickering, P. (2000). How to manage conflict. Petaling Jaya: Advantage Quest Sdn Bhd.

Preece, C.N., \& Hasan, S.F. (2010). Business development opportunities through pursuit of joint venture initiatives in construction. Paper presented at The Sixth International Conference on Multi-National Joint Ventures for Construction Works. Kyoto, Japan.

Shih, H., \& Susanto, E. (2010). Conflict management styles, emotional intelligence and job performance in public organizations. International Journal of Conflict Management, 21(2), 147-168.

Simmons \& Simmons (2014). Joint venture and shareholder disputes. Retrieved 24 January, 2014, from http://www.simmonssimmons.com/en/Services-and-Sectors/Dispute-Resolution/Joint-Venture-and-Shareholder-Disputes.

Stewart, M. R., \& R. D. Maughn (2011). International joint ventures, A Practical Approach, 6. 
Thomas, K. W. (1976). Conflict and conflict management. In M.D. Dunnette (Ed.), Handbook of Industrial and Organizational Psychology (pp. 889-935). Chicago: Rand McNally.

Turner, J. R., \& Simister, S. J. (2001). Project contract management and a theory of organization. International Journal of Project Management, 19, 457-464.

Wallace, R. L. (2004). Strategic partnerships: An entrepreneur's guide to joint ventures and alliances. Chicago: A Kaplan Professional Company.

Wolf, R. C. (2000). Effective international joint venture management: Practical legal insights for successful organization and implementation. New York: M. E. Sharpe Inc. 